Revista de Filosofía

ISSN: 0034-8244

https://dx.doi.org/10.5209/resf.75766

\title{
¿Qué implica la posibilidad de una «estética freudiana»? Aportes para la historia de la filosofía
}

Rubén C. Fasolino ${ }^{1}$

Recibido: 25 de septiembre de 2019 / Aceptado: 14 de marzo de 2020

Resumen. Lo que aquí se presenta es una introducción a las posibles implicaciones de una «estética freudiana», estética que estaría atravesada por el proyecto inacabado de Freud: la fundamentación de la Trieblehre.

Palabras clave: estética; pulsión; economía; das Unheimliche.

\section{[en] What does the possibility of a Freudian aesthetic theory entail? Contributions to History of Philosophy}

\begin{abstract}
This is an introduction to the possible implications of «Freudian aesthetics » which would be imbued by Freud's unfinished project: The foundation of Trieblehre.

Keywords: aesthetics; drive, economy, das Unheimliche.
\end{abstract}

Sumario: 1. Introducción; 2. De la posibilidad de una «estética freudiana»; 3. Otro rodeo por lo (in) hóspito; 4. Implicaciones de una «estética freudiana»; 5. Post-scriptum; 6. Referencias bibliográficas.

Cómo citar: Fasolino, R. C. (2021): “¿Qué implica la posibilidad de una «estética freudiana»? Aportes para la historia de la filosofía”, en Revista de Filosofia 46 (1), 191-212.

\footnotetext{
Iniversidad Complutense de Madrid rubencfa@ucm.es
} 
Antes de emprender este breve preámbulo de algo que no pretende ser más que un estudio introductorio, queremos dejar claro que nos ceñiremos únicamente, a partir de la cuestión que se desprende de los textos de Freud, a consideraciones que pueden ser del interés del vasto ámbito de la estética. Solo así podremos plantearnos, antes de dar por certera la existencia de una «estética freudiana», las implicaciones que esta tendría por el solo hecho de ser planteada. Dichas implicaciones estarán inevitablemente relacionadas con la cuestión que Freud interroga, y que tiene como finalidad lograr dar, del aparato psíquico, una exposición metapsicológica (metapsychologische Darstellung) como paso previo esencial a la fundamentación de la doctrina de las pulsiones (Trieblehre) ${ }^{2}$.

\section{Introducción}

Tomando como ejemplo la proverbial Introduzione al barocco de M. Praz, en la cual el célebre crítico literario utiliza el bello símil del curioso fenómeno de solemnes puertas arquitectónicas que se encuentran por la campiña romana, arcos majestuosos que, en contra de lo que podrían sugerir con su presencia, no conducen a ningún lugar, pues tras ellos solo se atisba un modesto sendero, vestigios de antiguos jardines casi desaparecidos y viñedos -bella metáfora de una imposible introducción al barroco ${ }^{3}-$, nosotros queremos esbozar lo mismo: introducir a una posible «estética freudiana» comporta diversas dificultades, y la primera de ellas es la de tener claro lo que significan tanto «estética» como aquello que comporta el nombre propio de Freud. Por otra parte, al preguntarnos por la posibilidad de esta extraña disciplina, entendemos que el corpus freudiano debe tener un peso dentro de la historia de la filosofía. Con todos estos reparos $-\mathrm{y}$ con otros que surgirán durante este breve camino-podríamos empezar de la siguiente manera:

Los intentos de fundamentar «estéticas» se cuentan ya innumerables. En nuestro caso, al preguntar por las implicaciones de una «estética freudiana», parecería que dominamos los términos que la componen. Nuestra pretensión, obviamente, no llega tan lejos: la estética es una disciplina que surge tarde, a destiempo, cuyo mayor valor, si no queremos seguir las sibilinas palabras de Heidegger en su Nietzsche ${ }^{4}$, es el de mostrar que, a partir de un determinado momento en la historia, los problemas se presentan como «problemas estéticos», es decir, como cuestiones que están constituidas a semejanza de un extraño nudo que comprende la teoría de las artes, la idea de lo bello y el problema del gusto, aspecto, este último, complejo, y que abre el campo de lo que Baumgarten nombrará en su Asthetica como «analogon rationis $\rangle^{5}$, algo que ya está descrito en los mismos términos en su Metaphysica allí cuando se refiere a este «análogo» como facultad inferior ligado a la facultad desiderativa $^{6}$. Esto, obviamente, equivaldría a reducir el asunto, pero lo que nos urge señalar, de momento, es que la importancia que la estética muestra en su surgimiento

\footnotetext{
Estos elementos serán aclarados en el Post-scriptum.

Cf. Introduzione al barocco (1956), en Praz (2002), p. 5.

«El hecho histórico de que toda estética verdadera, como por ejemplo la kantiana, se haga saltar a sí misma, es un signo inconfundible de que el preguntar de modo estético por el arte no es, por un lado, algo casual, pero, por otro, tampoco lo esencial.», Heidegger (1975), p. 154. Trad. (2000, 2005²), p. 128.

Baumgarten (2007), p. 11.

Baumgarten (1963), pp. 257-258.
} 
es el denotar, entre otros aspectos, la relevancia que la sensibilidad ha adquirido en relación con el conocimiento. Que la estética se haya ocupado siempre de la relación entre un saber que podríamos denominar intelectual, válido, o, con una palabra en este caso equívoca, «filosófico», y, por otra parte, con un saber sensual, impreciso, o, también en este caso recurriendo a un término equívoco, «poético», no creemos que sea una descripción incorrecta de esa zona de margen en la que gran parte de los estudios de estética se han movido. A partir de estas cuestiones, tendremos que elegir una vía y descartar otras con relación al significado de la palabra «estética». Respecto de este problema hay un punto de inflexión reciente en la querella de en qué consistiría la estética, si esta es, por ejemplo, una filosofía que interpreta las obras de arte (suponiendo de entrada un consenso que no es posible a menos que no se admita, de manera igualmente problemática, que «arte» es aquello que tiene cabida en el discurso institucional -museístico, ministerial, etc.-), incluyendo no solo la interpretación -infinita- de toda «obra de arte» y de su constitución como mediación sensible de la idea o, también, como el equilibrio precario entre el usar-de y el dejar-ser, sino, también, el problema del artista, el del proceso creativo y, por último, el del espectador. Pero se dirá que estos ámbitos han terminado resolviendo a la estética en una «hermenéutica del arte». Entonces, segunda posibilidad, la estética es la disciplina que también se ocuparía de la idea de lo bello (tò kalón) como aquel ềdos que, por su mismo aparecer, interrumpe el obvio y común darse de las cosas con el doble y contrario movimiento de una hipnosis que arrastra, desposeyendo al caído, en sus fauces o, al contrario, una interrupción fruto de la contemplación de la belleza como kósmos, el «a cada cosa y cada quién según su naturaleza», momento en el que se desvela la correcta trabazón (dike), la justicia (dikaiousine) $\mathrm{y}$, entonces, la verdad (aletheía) ${ }^{7}$. Pero entonces podríamos preguntarnos ¿por qué hablar de estética y no de ontología de lo bello? Por último, el hallazgo de Baumgarten que, retomando los elementos de la teoría de las artes y de la crítica del gusto con relación al ideal de lo bello, añade la cuestión ya mencionada del analogon rationis para hacer de su estética la hermana menor de la lógica ${ }^{8}$ como partes integrantes de la metafísica. Y también en este punto surgirá la pregunta: ¿en qué se diferencia el análisis del análogo de la razón identificado con la sensibilidad y las facultades inferiores (en particular la facultad de evocar imágenes en ausencia del referente) de, por ejemplo, una psicología de la percepción o, también, de lo ya mencionado en los tratados de poética acerca de la facultad imaginativa? ${ }^{9}$ Por no mencionar que estos aspectos ya se abarcaron por el mismo Baumgarten en obras cuales las Meditationes philosophicae de nonnullis ad Poema pertinentibus (1735) $\mathrm{y}$, sobre todo, en su Metaphysica $(1739)^{10}$. Parece que a la estética le salen constates competidores o que ya estaban -la ontología, la poética, la retórica- o que surgen con ella -la hermenéutica- para, ya adentrados en el siglo XIX, hermanarse con la ética. Decíamos que hay un punto de inflexión reciente en esta eterna querella por los límites de la estética -algo así como una «pregunta por la estética»-, el texto de M. Ferraris titulado Estetica razionale, publicado en 1997 y reeditado en 2011 con una nueva premisa y un epílogo. Habrá que aclarar algo sobre un texto de casi seiscientas

\footnotetext{
Para estos desarrollos reenviamos a Martínez Marzoa (1995), pp. 39-43.

Baumgarten (2007), pp. 17-18.

Cf. Franzini y Mazzocut-Mis (1996).

10 Cf. Baumgarten (1963).
} 
páginas que defiende una tesis difícil de asumir: la estética como filosofía primera. Primera por una astucia, pues en la filosofía entendida como ontología y metafísica de lo que se trata es cómo una esencia llega a presencia, invirtiendo el paradigma y haciendo de la estética la disciplina que debe ocuparse de la superficie de inscripción en la que tanto la imaginación como la memoria son funciones de la huella. Este aspecto es central, pues, además de recuperar una «estética fuerte» que -y no es asunto de este trabajo- reabriría la discusión con el Kant de la primera y de la tercera Crítica, uniría también de manera casi indisoluble la estética a la cuestión primera de Freud: las huellas (Spuren) y sus transposiciones (Umsetzungen) y reescrituras (Umschriften ${ }^{11}$ como el origen de lo que denomina Das Unbewußte (y, entonces, del problema de las transposiciones y transcripciones (Niederschriften) de una localidad a otra, es decir, del problema económico del comercio entre localidades psíquicas ${ }^{12}$ ). Es de esto, de la extraña economía de las huellas (¿sensibles?) que promueve y diferencia los objetos de las metas -no solo en el ámbito del deseo, sino también en el de la decisión y en el del conocimiento- que interrogamos una posible «estética freudiana», cuyas comillas indican gráficamente la pregunta por su posibilidad y, entonces, por las implicaciones que esta tendría.

Será entonces desde aquí, de aquello que hace hendidura en un receptáculo, punto, creemos, que es el inicio de Freud para aquello que es su cuestión, el aparato psíquico, de dónde nosotros partiremos para interrogar una posible «estética freudiana» como un capítulo abortado de la estética como aisthesis de la inscripción o estética de la huella, disciplina que no solo se ocuparía del análogo de la razón como lo otro que completa y que, en algunos casos, podría sobrepasar a la razón -una sensibilidad necesaria que puede tornarse excedente y excesiva, tal y como podría ocurrirle al inconsciente freudiano como depositario del Wunscherfüllung que no se combina con ninguna Befriedigung - terminando por cuestionar la primacía de la «razón»o de la «conciencia»y de sus objetos intencionales (y, ya lo advertimos, no iremos por esta senda); se trata de una «estética freudiana» que vuelve a interrogar el problema, la pulsión (y su no fundamentada «doctrina de las pulsiones») como aquello que rompe el posible trabajo entre el principio de placer y el principio de realidad, el llamado por Freud «jenseits» del principio de placer, la Wiederholungszwang como el más soberano fondo del psiquismo, el analogon no solo de la razón, sino de su organización más próxima, ese enjambre de transcripciones movidas y removidas por el más allá del principio de placer, que Freud llamó «el inconsciente». Que dicho principio soberano, además, Freud lo descubriera en su ligazón con el comienzo de la simbolización -el Fort/da - y que la entrada en la lengua implique, además, el acceso en o de la Todestriebe ${ }^{13}$, es algo sin duda problemático tanto para la teoría como para la clínica psicoanalítica, pero que en este contexto tomaremos como uno de los puntos a interrogar para la pregunta por las implicaciones de una «estética freudiana», de lo propiamente excedente y que termina por situarse en una línea que no parece ser ni psíquica ni somática, pero que implica una inscripción, una marca, una huella desde donde se constituiría el par presencia/ausencia o vida/muerte:

\footnotetext{
Ver, al respecto, la carta de Freud a Fliess fechada 6/12/1896, cf. Freud (1986), pp. 216-219.

Cf. Freud (1952e), pp. 272-273.

Estos aspectos serán retomados más adelante.
} 
La meta de toda vida es la muerte; y, retrospectivamente: Lo inanimado estuvo ahi antes que lo vivo.

En algún momento, por una intervención de fuerzas que todavía nos resulta enteramente inimaginable, se suscitaron en la materia inanimada las propiedades de la vida. Quizá fue un proceso parecido, en cuanto a su arquetipo, a aquel otro que más tarde hizo surgir la conciencia en cierto estrato (Schicht) de la materia viva. La tensión así generada en el material hasta entonces inanimado pugnó después por nivelarse; así nació la primera pulsión, la de regresar a lo inanimado (Leblosen zurückzukehren). ${ }^{14}$

Hablamos de estratos, algo cercano a una estética en el sentido de la aísthesis en la contraposición entre los noetá y los aisthetá, contraposición que lo es también de lo claro y de lo oscuro, de lo evidente y de lo confuso, de esa zona que no debe terminar de emerger pues es la depositaria de los affectus, de las emociones y de los apetitos sensitivos, elementos que nos pueden llevar a confusión. Permaneciendo en este aspecto de la palabra «estética», E. Franzini presenta su historia como el viaje desde la regularidad - o de como los modernos, en general, comprendimos a los antiguos- hasta la irregularidad -o de como los modernos somos en cada caso nosotros mismos-. En definitiva, un viaje que representa las fluctuaciones entre lo psíquico y lo somático o entre la razón y la pasión, y que en un determinado momento se convirtieron en síntoma estructural, en un más allá del principio de placer -añadimos nosotros- que no podrá ya regularse con el principio de realidad. En el fondo, la estética también fue esto incluso antes de que se la bautizara con este nombre en 1735, un saber hacer con lo sensual tanto en su aspecto placentero como en su faceta más arrebatadora y desgarradora, un saber que no solo implicaba la cuestión del (buen) gusto, sino un ideal de perfección que requiere una ética y una política.

También hay que precisar lo siguiente $-\mathrm{y}$ esto tiene que ver con lo que ya apuntamos, que la estética nació a destiempo-: lo que ahora cae bajo el rótulo de «reflexión estética» (teoría de las artes, crítica del gusto y de los sentidos en general, idea de lo bello), precede a la fundamentación de la palabra Aesthetica llevada a cabo por Baumgarten ${ }^{15}$. Este filósofo «solo» quiso ocuparse, quizás desde un proyecto de sistematización de los saberes producidos por la Aufklärung ${ }^{16}$, de aquella parte que produce conocimiento pero que es menos clara y distinta. Esta ocupación procedió de una perspectiva más general que incluía, como ya nos hemos referido, una Metaphysica para luego dirigirse hacia -siguiendo la terminología de Leibniz ${ }^{17}$ lo que concierne a la aísthesis, con el propósito de identificar las sensaciones que podemos definir como «claras» (en contra de las «oscuras»), para continuar hacia las sensaciones «distintas»y analizables (en contra de la «confusas»), llegando

14 Freud (1952g), p. 40. Trad. (1979f), p. 38.

15 Este es un aspecto esencial en el cual no podremos ahondar, pero es importante denotar que los ideales de conjugar en una ética el antiguo -o así imaginado-ideal de perfección (estético), llegaron a su máximo apogeo, al menos en lo que denominamos «modernidad», en el Antiguo Régimen. Las palabras y las fórmulas eran otras: douceur de vivre, loisir, enjouement, ruelle, honnêteté, politesse, etc., todas ellas para indicar lo que ahora pondríamos bajo el rótulo de «ideal de perfección ético y estético». Obviamente su uso testificaba que aquello que indicaban se encontraba ya muy debilitado y sin posibilidad de vuelta, pudiendo explicitar solo la lejanía que había entre la mera posibilidad y la real composición de dicho ideal de perfección estético. Para este y otros temas afines, reenviamos al enorme trabajo de Craveri (2001), pp. 21-30, 55-76 y 316-358.

16 Cf. Ferraris y Kobau (2001), p. 209 y sigs.

17 Cf. Meditationes de cognitione, vertitate et ideis (1684). 
finalmente a una «adecuación» (en contra, como es obvio, de la «inadecuación»). En este intento de dar una lógica a las sensaciones, casi la búsqueda de un principio organizativo que permitiera reconducir a unidad los elementos de las sensaciones -uno de los ejes de la Aesthetica de Baumgarten ya anticipado en su Metaphysica ${ }^{18}$ se reproduce, aunque de manera implícita, el antiguo problema: el desacuerdo que los modernos perciben desde siempre entre la filosofía y la poesía. No es el caso aquí de criticar la idea de una disciplina filosófica que hoy sigue vigente, o de volver a la $K r V$ y a su $\S 1$ de la «Estética trascendental», donde la palabra «estética» solo tiene sentido como el análisis de las condiciones de la posibilidad de la sensibilidad por ser uno de los dos troncos del conocimiento. Simplemente queremos subrayar que, tal y como ya lo apuntamos, el hecho de que la denominada "reflexión estética» preceda a la «disciplina estética» pensada por Baumgarten, nos conduce siempre a preguntarnos por los límites y los objetos de la estética, incluso optando por una «estética fuerte» como disciplina del analogon rationis que serviría de punto de anclaje entre la metafísica y la lógica baumgarteanas.

También el psicoanálisis tiene una parecida marca de nacimiento, pues una cierta indefinición rodea sus objetos. Este método terapéutico surgió como la atención teórica y metodológica hacia ciertos fenómenos residuales y, generalmente, marginales: los sueños, los lapsus, los olvidos, un inocente chiste, etc. Nada de esto es nuevo: el método terapéutico creado por Freud percibió que podía encontrarse, al igual que para la razón y los enlaces del intelecto, una lógica de las formaciones oníricas y de lo que hoy denominamos como «formaciones del inconsciente». Pero, tanto la estética como el psicoanálisis, desde su surgimiento, pasan por constantes exámenes y controles. Incluso para algunos especialistas tanto la una como el otro no deberían ser ni una disciplina filosófica - por no poder constituirse ni una ciencia sobre el gusto y lo bello, ni sería posible ocuparse de la sensibilidad como una parte del conocimiento aislándola, de manera artificial, del intelecto-, ni un método terapéutico -por no poder el psicoanálisis fundamentar sus conceptos (que fueron «oscuros» desde su nacimiento)-. Es decir, a ambas disciplinas, en contra de la voluntad de sus respectivos fundadores, les pertenece la oscuridad, la vaguedad, la marginalidad al no poder fundamentar sus objetos de estudio en conceptos. Podríamos continuar sobre estos aspectos o virar hacia las causas que originaron ambas disciplinas que aquí cuestionamos bajo un único rótulo $\mathrm{y}$, entonces, preguntarnos si la estética surgió en la historia porque debió ordenar aquello que se iba gestando alrededor de lo que solemos llamar «sensibilidad» y sus vastos aledaños o si, por el contrario, es el establecimiento de la estética que llevó a la «sensibilidad» a devenir objeto de reflexión.

No parece razonable, habida cuenta del extenso material literario, ensayístico y filosófico que poseemos, aducir que la sensibilidad devino tema de interrogación autónomo gracias al surgimiento de la estética, sino más bien lo contrario: frente a un elemento tan grande y perturbador como la «sensibilidad» y su larga corte de acólitos, un saber positivo se organizó -o trató de hacerlo- para dar cuenta de ella y de todos sus entresijos. Lo que sí parece claro es que los tres grandes ejes de la estética -el arte, lo bello, la sensibilidad-se tornaron objeto de reflexión privilegiada, en su fuerte anudamiento, a partir de un determinado momento de la historia. Las causas de todo esto van mucho más allá del objetivo del presente artículo y la breve

18 Baumgarten (1963), p. 187. 
reflexión propuesta nos sirve solo para indicar que con el psicoanálisis ocurrió algo similar: su surgimiento se debió a la confrontación con un discurso -con el tiempo denominado «del malestar»-que debía ser escuchado, pues reclamaba nuevas orejas. Este discurso, generalmente encarnado en sujetos femeninos, es el de una voz que pone en discusión determinados preceptos o dogmas que perduraban desde bastante tiempo atrás. Lo que es digno de notar, de momento, es que, en este camino de otorgarle voz a un discurso silenciado, un discurso particularmente sensual y a veces tildado de «no razonable», Freud tuvo que probar distintas vías -algunas de las cuales bastante asentadas-, caminos que desestimó pero que hoy siguen vigentes tanto en la manera de «gobernar» como en la de «educar»: nos referimos a la hipnosis y a la sugestión. Freud tuvo que descartar, en la escucha de ese discurso para él revelador y lleno de implicaciones, tanto la hipnosis como la sugestión y abogar por una escucha diferente, por un tratamiento que, en la praxis, denominó «asociación libre», que libre no era, pero ayudaba a poner en claro ciertas predeterminaciones de lo que quedó ligado para la posteridad a un término ya muy sobrecargado por la tradición: das Unbewußtsein (lo inconsciente).

Últimamente se habla de malestar en la estética -algo que se puede alargar, en general, a la filosofía y al psicoanálisis-. Este malestar, en la estética, está relacionado con la desazón que sus objetos directos de ocupación (en particular el arte) atraviesan, pero es significativo que la estética, al menos desde su fundamentación académica, entrara en crisis muy pronto incluso si su objeto prioritario no fue el arte, sino más bien la interpretación - poética y retórica- del problema formal puesto ante nosotros por el objeto artístico en vistas de una correcta gnoseología. Con el psicoanálisis pasó algo parecido y esto también se debió a sus objetos de interés, en particular por lo que está a la base del inconsciente entendido como lo Unbekannt (lo desconocido) de las Umsetzungen (transposiciones) que constantemente se mueven (tópicamente) y remueven (dinámicamente) debido a una ley económica que nos lleva a la auténtica roca metafísica de la especulación freudiana: la Trieblehre.

Antes de finalizar esta introducción que no defraudó las expectativas y, efectivamente, mantuvo las comillas a la «estética freudiana» como disciplina de las inscripciones, queremos disipar una cuestión antes de proseguir (el resto de los hilos pendientes ya se retomarán a continuación): la relación de Freud con el arte. Nadie puede dudar de la importancia y las influencias que «el» psicoanálisis tiene y ha tenido en la crítica de arte. La bibliografía sobre esta cuestión es casi interminable y está repleta de nombres resonantes de la talla de Th. Adorno, E. Gombrich, R. Arnheim y S. Kofman entre otros. Las conclusiones -las muchas que hay- sobre la realización artística, la interpretación de una obra de arte y las teorías freudianas de la sublimación no deben perder de vista un asunto fundamental: los escritos freudianos que hay sobre las interpretaciones de obras de arte o la psicología del artista y de sus génesis creativa están bastante impregnados de tesis idealistas y románticas, por ejemplo, el fantaseo como ámbito de lo irreal infantil que es censurado por la realidad y que sobrevive en el poeta, cuyas creaciones son el receptáculo del placer consolatorio y regresivo que nos procura la fruición artística. Pues: "Man darf sagen, der Glückliche phantasiert nie, nur der Unbefriedigte.»" . Elementos, estos, que encontramos, entre otros, en Ferraris ${ }^{20}$. Como tampoco habrá

\footnotetext{
«El hombre feliz no fantasea, solo el insatisfecho lo hace», en Freud (1952d), p. 216. Trad. (1979b), p. 129.

20 Ferraris $\left(1997,2011^{2}\right)$, pp. 140-141.
} 
que pensar, quedándonos en el mismo ámbito, que en el proceso primario, haya algún valor artístico, aspecto ya sugerido por E. H. Gombrich en un texto de $1966^{21}$. Nos parece que los primeros acercamientos freudianos al arte y a la interpretación de obras o, incluso, a la génesis del proceso creativo, fueron una corroboración de diversos elementos esenciales de la teoría psicoanalítica que, poco a poco, se iban esclareciendo, elementos que, al menos hasta la fundamentación del «concepto» de pulsión, supusieron una tarea constante ${ }^{22}$. Si no, de poco servirán estas palabras de Freud:

Quiero anticipar que no soy un conocedor de arte, sino un profano. He notado a menudo que el contenido de una obra de arte me atrae con mayor intensidad que sus propiedades formales y técnicas, a pesar de que el artista valore sobre todo estas últimas. En cuanto a muchos recursos y efectos del arte, carezco de un conocimiento adecuado. Me veo precisado a decir esto para asegurarme una apreciación benévola de mi ensayo. ${ }^{23}$

O, incluso, la advertencia que resuena más misteriosa y casi capturada por un olvido que leemos en Lo ominoso: «Es muy raro que el psicoanalista se sienta proclive a indagaciones estéticas, por más que a la estética no se la circunscriba a la ciencia de lo bello, sino que se la designe como doctrina de las cualidades de nuestro sentir. $»^{24}$. Sin duda sorprende encontrar esta frase en un pasaje que retomaremos más adelante y que pertenece a un texto que sigue propiciando más que otros una reflexión infinita del nexo psicoanálisis-arte.

Lo que queda aclarado es que nunca es fácil utilizar los recursos que ofrece el arte, ni saber cómo acercarse a las interpretaciones que un aparato teórico, el de Freud en el caso concreto, busca en su apoyo al ámbito artístico. La indestructibilidad del deseo inconsciente que me sobre-determina cual voz o guía exterior que, finalmente, se revelará como una materialización de lo anímico profundo y desconocido, no quedará más aclarada por recurrir a la tragedia sofoclea de Edipo o al Hamlet de Shakespeare. Es opinión asentada y común que el acudir al arte no sea un recurso entre otros ${ }^{25}$, sino siempre el último de estos que demuestra que hay cosa, asunto, cuestión que requiere un «concepto» que jamás logra establecerse como este o aquel concepto que define este o aquel objeto, sino que se pone en juego la posibilidad misma del establecer concepto. Esta puesta en juego que acontece con la mayoría de los recursos descriptivos del psicoanálisis (Unbewußte, Trieb, Wiederholungszwang, etc.) son la indicación flagrante de que hay cosa, asunto, cuestión para la que hay que seguir buscando concepto. Por otra parte, y siempre en relación con la cuestión psicoanálisis-arte, tampoco habrá que olvidar, tal y como apunta P. Ricoeur entre otros, la modestia, las protestas de cierta torpeza y el resultado de fracaso -seguramente relevante- del psicoanálisis aplicado al arte ${ }^{26}$. Siguiendo por estos derroteros, el ámbito del fantaseo, tan importante para Freud, se basa en ser una

\footnotetext{
Cf. Gombrich (1966), p. 27.

22 Hablamos del periodo comprendido entre los años 1909-1914. El texto de Das Unheimliche tiene un lugar de excepción que ya comentaremos más adelante. Para estos aspectos reenviamos al texto de Pizzo Russo (2015), pp. 10-11.

23 El Moisés de Miguel Ángel (1913), cf. Freud (1952e), p. 172. Trad. (1980a), p. 217.

24 Lo ominoso (1919), cf. Freud (1952f), pp. 230-231. Trad. (1979d), p. 219.

25 Aspecto que también recuerda J. Rancière (2001), p. 9 y sigs.

26 Cf. Ricoeur P. (2008).
} 
isla feliz o suspendida en ese infinito trabajo entre el principio de placer y el de realidad, trabajo que, nos parece, es puesto en seria duda por el más allá del principio de placer. Una vez introducido el problema de la pulsión y de su funcionamiento, no parece haber reales posibilidades de "progresos» o «trabajos» si, el fondo del aparato anímico, es compulsión a la repetición de un pasado que nunca fue presente solo alcanzable en un futuro o, dicho de otro modo, en la búsqueda incesante de lo novedoso se trata de hallar la antigua satisfacción perdida, quedando apresado en lo único que realmente se da, que hay: la repetición y su coacción incesante, muestras de una economía pulsional cuyas «ganancias» resultan enigmáticas. En el siguiente apartado, trataremos de mostrar qué pretendemos corroborar, no sin antes citar este extracto de la Presentación autobiográfica:

No hay para el psicoanálisis necesidad más sentida que la de una doctrina sólida de las pulsiones sobre la cual se pudiera seguir construyendo. [...] me atreví a intentar una «metapsicología». Llamé así a un modo de abordaje en que cada proceso anímico es apreciado siguiendo las tres coordenadas de la dinámica, la tópica y la economía, y vi en ello la meta máxima asequible a la psicología. El ensayo quedó como un torso; lo interrumpí tras unos pocos trabajos («Pulsiones y destinos de pulsión» [1915c], «La represión» [1915d], «Lo inconsciente» [1915e], «Duelo y melancolía» [1917e], etc.), e hice bien, sin duda, pues aún no había llegado el tiempo para tal formulación teórica. ${ }^{27}$

Quizás tampoco en lo sucesivo fue posible, si bien los intentos fueron continuos, llegar a tal formulación teórica. De lo que no debe quedar duda -y hay muchas páginas de Freud que lo corroboran sin posibilidad de apelación- es que su única atención se centró en ese «concepto» oscuro:

Queda excluido que en esta Presentación autobiográfica trate acerca de los progresos del psicoanálisis en su segunda época con la misma prolijidad que acerca de su lenta edificación durante la primera, llenada por mi sola actividad. Únicamente me siento autorizado a mencionar aquí los nuevos logros en los que aún tuve participación destacada, o sea, sobre todo, los referidos al ámbito del narcisismo, de la doctrina de las pulsiones y de la aplicación del psicoanálisis a las psicosis. [...] Es verdad que en este último decenio he realizado una buena porción de trabajo analítico importante, como la revisión del problema de la angustia en Inhibición, síntoma y angustia (1926d), o que en 1927 conseguí el esclarecimiento terso del «fetichismo» sexual [1927e]; no obstante, es correcto decir que desde la postulación de las dos clases de pulsión (Eros y pulsión de muerte) y la descomposición de la personalidad psíquica en un yo, un superyó y un ello (1923b) no he brindado ya ninguna contribución decisiva al psicoanálisis: lo que después he escrito habría podido omitirse sin daño u otros lo habrían ofrecido pronto. ${ }^{28}$

\section{De la posibilidad de una «estética freudiana»}

A partir de un bello escrito de Agamben tendremos la posibilidad de continuar nuestra aportación y de ir atando cabos sueltos, aprovechándonos de un extravío del

27 Freud (1952h), pp. 84-85. Trad. (1979f), pp. 53-55. Esta exigencia ya quedó aclarada en el comienzo de Pulsiones y destinos de pulsión (1915), cf. Freud (1952e), pp. 210-211. Trad. (1979c), p. 113.

28 Ibid., pp. 51-52 y 67-68 de la traducción castellana. 
autor que se tornará evidente con el paso de las páginas. El texto en cuestión se titula Gusto $^{29}$, un breve e inteligente panfleto que se centra en la cuestión baumgartiana de interrogar el conocimiento otro, la sensibilidad -en particular el gusto-, conocimiento para el cual Agamben encuentra el sugerente binomio «significante excedente». Así la estética sería la disciplina que se ocupa de un saber que siempre excede. Esta es unas de las líneas que el autor propone, línea que nos parece la más sugestiva por apoyarse en una terminología que no existía en tiempos de Baumgarten y que ya es indispensable para nuestra reflexión. Lo que los sentidos otorgan pertenece al material significante que no llegaría a enlazarse completamente a un significado y no conformaría, a todos los efectos, entidad lingüística enteramente transmisible. Siempre quedaría un resto, un excedente, algo que retorna y que sigue insistiendo por ser un "puro significante» ${ }^{30}$, es decir, una marca, o, también, por ser participio presente del verbo significar, estando, por tanto, siempre en acto. Se trata de un saber que, aunque no pueda fijarse y otorgar validez de conocimiento, hace mediciones y juzga con cierta insistencia situándonos en un énfasis perpetuo a algo que excede y que, por ello mismo, asedia. Por supuesto que no es nuestra intención analizar pormenorizadamente todas las vías propuestas por Agamben, pero como era de esperar, en su breve texto era solo cuestión de tiempo que Freud y Lacan hiciesen su aparición, y para lo que aquí se discute ayudará el hecho de que Agamben cite de manera incompleta un texto de Freud, cita que, al no completarse, cambia su sentido. De momento propondremos solo lo que G. Agamben reproduce de Freud:

\begin{abstract}
Al reconocer el inconsciente como lugar de la economía del placer, el psicoanálisis se sitúa en el límite entre la estética y la economía política, entre el saber que no se sabe y el placer que no se goza. (La idea de «una estética guiada desde el punto de vista económico», que Freud formula en el capítulo II de Jenseit des Lunstprinzips [1920], es, desde esta óptica, ciertamente significativa $)^{31}$.
\end{abstract}

Todo lo que nos podía aportar este texto termina aquí. La cita es sugerente y nos recuerda que Freud, además de las metáforas escriturales que recorrieron toda su obra, también manejó un arsenal repleto de términos provenientes del ámbito económico: «comercio» («Verkehr») y «transferencia» (Übertragung) asomarán siempre a lo largo del recorrido freudiano, y el primero de los términos cobrará su importancia fundamental en el capítulo sexto de la obra Das Unbewußtsein titulado Der Verkehr der beiden Systeme (El comercio entre los dos sistemas). No creemos que este escrito de Freud sea un texto entre otros, pues es aquí donde queda zanjado que el inconsciente tiene la estructura de un lenguaje ${ }^{32}$ :

[...] la representación consciente abarca la representación-cosa (Sachvorstellung) más la correspondiente representación-palabra (Wortvorstellung), y la inconsciente es la representación-cosa sola. El sistema Icc contiene las investiduras de cosa de los objetos,

\footnotetext{
Agamben (2017), p. 52.
}

30 Ibid., p. 47. No comentaremos en ningún caso el uso de la terminología de Saussure propuesto por G. Agamben, simplemente subrayamos el hecho de que, también en este caso, la lingüística inaugurada por Saussure sea indispensable al proceder del autor.

$31 \quad$ Ibid., p. 52.

32 Decir en modernidad que «el inconsciente está estructurado como un lenguaje» equivale a decir que los dos términos poseen la misma constitución -la ya recordada más arriba: lo Umsetzung-- 
que son las investiduras de objeto primeras y genuinas; el sistema Prcc nace cuando esa representación-cosa es sobreinvestida por el enlace con las representaciones-palabra que le corresponden [mit den ihr entsprechenden]. Tales sobreinvestiduras, podemos conjeturar, son las que producen una organización psíquica más alta y posibilitan el relevo del proceso primario por el proceso secundario que gobierna en el interior del Prcc. Ahora podemos formular de manera precisa eso que la represión, en las neurosis de trasferencia, rehúsa a la representación rechazada: la traducción en palabras, que debieran permanecer enlazadas con el objeto. La representación no aprehendida en palabras, o el acto psíquico no sobreinvestido, se quedan entonces atrás, en el interior del Icc, como algo reprimido. ${ }^{33}$

Así es como Freud comprende la nueva puesta en "concepto» de lo inconsciente -antes descrito como los comercios entre la agencia reprimida y la agencia represora, es decir, solo en términos descriptivos y dinámicos-: los des-ajustes entre las (representaciones de) palabras y las (representaciones de) cosas. Pero es también el texto - no por casualidad- donde se establece el nuevo programa de investigación del psicoanálisis, proyecto que persigue el poder dar una descripción de los procesos psíquicos según los aspectos «dinámicos», «tópicos»-elementos ya presentes- y «económicos»-aspecto novedoso-. A esto deberá llamarse, de ahora en adelante, metapsicología.

Volviendo a la cita que nos propone G. Agamben, cita que todavía dejaremos incompleta y sin esclarecer, lo que acabamos de leer nos ayuda a entender la importancia que la pulsión cobra en Freud, tanto que él mismo podrá escribir en Más allá del principio de placer, lo siguiente:

La pulsión reprimida nunca cesa de aspirar a su satisfacción plena, que consistiría en la repetición de una vivencia primaria de satisfacción; todas las formaciones sustitutivas [Ersatzbildungen] y reactivas [Reaktionsbildungen], y todas las sublimaciones [Sublimierungen], son insuficientes para cancelar su tensión acuciante, y la diferencia entre el placer de satisfacción hallado y el pretendido engendra el factor pulsionante, que no admite aferrarse a ninguna de las situaciones establecidas, sino que, en las palabras del poeta, «acicatea, indomeñado, siempre hacia adelante» (Mefistófeles en Fausto, parte I, escena 4$).{ }^{34}$

Esta cita es muy significativa, pues de manera tajante indica que no hay nada que pueda hacerse en contra o a favor de la pulsión ${ }^{35}$ al tratarse de una fuerza de choque constante $^{36}$. Este concepto se describe pormenorizadamente en Pulsiones y destinos de pulsión, para corroborar que el objeto de la pulsión jamás podrá coincidir con la meta de esta ${ }^{37}$. Este misterioso y extraño desacuerdo tiene raíces muy profundas

33 El inconsciente (1915), cf. Freud (1952e), p. 300. Trad. (1979c), p. 198. El pasaje «esa representación-cosa es sobreinvestida por el enlace con las representaciones-palabra que le corresponden» es cuanto menos curioso, y es desde aquí que parte la sentencia lacaniana: l'inconscient c'est le discours de l'Autre, en tanto que es el otro de la palabra (Autre) que, al traducirme, me hace surgir incompleto en el código del que es portador, pues la verdad está en él como detentor de las correspondencias.

34 Freud (1952g), pp. 44-45. Trad. (1979e), p. 42.

35 Este aspecto pulsivo o pulsionante también fue analizado en más de una ocasión por Derrida -omito por obviedad el nombre de Lacan-. En particular en: Derrida (1995), pero también en otras obras como La carte postale, Psyché, Inventions de l'autre y Voyous. Deux essais sur la raison.

36 Pulsiones y destinos de pulsión (1915), cf. Freud (1952e), p. 211. Trad. (1979c): p. 114.

37 Ibid., pp. 118-119 de la traducción castellana. 
en la obra freudiana: nos baste recordar que la Befriedigung, la satisfacción de las necesidades materiales jamás coincide con la Wunscherfüllung, el cumplimiento alucinatorio del deseo. De esto tenemos huellas en la Traumdeutung, en la larga cita que proponemos:

La excitación impuesta \{setzen\} por la necesidad interior buscará un drenaje en la motilidad que puede designarse «alteración interna» o «expresión emocional». El niño hambriento llorará o pataleará inerme. Pero la situación se mantendrá inmutable, pues la excitación que parte de la necesidad interna no corresponde a una fuerza que golpea de manera momentánea, sino a una que actúa continuadamente. Sólo puede sobrevenir un cambio cuando, por algún camino (en el caso del niño, por el cuidado ajeno), se hace la experiencia de la vivencia de satisfacción que cancela el estímulo interno. Un componente esencial de esta vivencia es la aparición de una cierta percepción (la nutrición, en nuestro ejemplo) cuya imagen mnémica queda, de ahí en adelante, asociada a la huella que dejó en la memoria la excitación producida por la necesidad. La próxima vez que esta última sobrevenga, merced al enlace así establecido se suscitará una moción psíquica que querrá investir de nuevo la imagen mnémica de aquella percepción y producir otra vez la percepción misma, vale decir, en verdad, restablecer la situación de la satisfacción primera. Una moción de esa índole es lo que llamamos deseo; la reaparición de la percepción es el cumplimiento de deseo, y el camino más corto para este es el que lleva desde la excitación producida por la necesidad hasta la investidura plena de la percepción. Nada nos impide suponer un estado primitivo del aparato psíquico en que ese camino se transitaba realmente de esa manera, y por tanto el desear terminaba en un alucinar. Esta primera actividad psíquica apuntaba entonces a una identidad perceptiva, o sea, a repetir aquella percepción que está enlazada con la satisfacción de la necesidad.

Una amarga experiencia vital tiene que haber modificado esta primitiva actividad de pensamiento en otra, secundaria, más acorde al fin \{más adecuada\}. Es que el establecimiento de la identidad perceptiva por la corta vía regrediente en el interior del aparato no tiene, en otro lugar, la misma consecuencia que se asocia con la investidura de esa percepción desde afuera. La satisfacción no sobreviene, la necesidad perdura. Para que la investidura interior tuviera el mismo valor que la exterior, debería ser mantenida permanentemente, como en la realidad sucede en las psicosis alucinatorias y en las fantasías de hambre, cuya operación psíquica se agota en la retención del objeto deseado. Para conseguir un empleo de la fuerza psíquica más acorde a fines, se hace necesario detener la regresión completa de suerte que no vaya más allá de la imagen mnémica y desde esta pueda buscar otro camino que lleve, en definitiva, a establecer desde el mundo exterior la identidad [perceptiva] deseada. ${ }^{38}$

Lo que acabamos de leer nos pone sobre el aviso de que siempre nos encontramos con la otra satisfacción, con la otra escena, pues se trata de la escena recreada por el hecho de que la satisfacción hallada no coincide con la esperada: «cuya imagen mnémica queda, de ahí en adelante, asociada a la huella que dejó en la memoria la excitación producida por la necesidad». La satisfacción siempre es «vivencia de», pero nunca satisfacción o placer pleno en tanto que lo hallado no coincide con el

38 Freud (1952b), pp. 570-572. Trad. (1979a), pp. 557-558. Este aspecto es también comentado en el Diccionario de psicoanálisis, cf. Laplanche y Pontalis (2004), p. 134. 
objeto ni la meta con el fin ${ }^{39}$. Lo que queda, entonces, parece algo más cercano a la fantasmagoría y al simulacro. Quizás ahora puedan sonar más esclarecedoras las palabras de la cita que propusimos antes y que reproducimos en parte: «todas las formaciones sustitutivas y reactivas, y todas las sublimaciones, son insuficientes para cancelar su [de la pulsión] tensión acuciante». Esto es altamente significativo porque muestra que ningún comercio íntimo y exterior como actividades de ocio de todo tipo (redes sociales, pertenencia a comunidades, a tribus urbanas, hobbies y un largo etcétera), así como las proclamas políticas, las manifestaciones e incluso las reivindicaciones -formaciones sustitutivas y reactivas-, e incluso las sublimaciones -aquí la gama es también vastísima: producciones intelectuales y artísticas de todo tipo, hedonismo, etc.- son suficientes para aplacar la pulsión, su factor pujante. Sobre esto la obra de Lacan es bastante esclarecedora, en particular allí donde nos enfrenta a lo que él produjo como grafo - o grama-del deseo ${ }^{40}$, un curioso recorrido para, desde Freud, volver a la dialéctica del amo y del esclavo hegeliana aprendida con Kojève y, una vez recorrida esta, poder volver a Freud.

¿Qué podría significar una «estética freudiana» guiada desde un punto de vista económico, tal y como la cita de G. Agamben quiere indicar? De momento seguimos encontrándonos en aporía, pues la pulsión es la ley de la satisfacción forzosa por la cual no hay coincidencia entre los fines y metas de nuestras satisfacciones $-\mathrm{O}$ vivencias de ellas-, y, lo que es casi peor, de los objetos de los que nos servimos para ello: es siempre el deseo de otra cosa que siempre falta. Parece no haber progreso, si bien sí tenemos un cierto desarrollo en nuestro ingeniárnoslas con aquello de lo que describe Freud como insuficiente: formaciones sustitutivas, reactivas, sublimaciones, etc.; es decir, toda la gama de artificios para recobrar o alcanzar un determinado placer. ¿La «estética freudiana» guiada por un punto de vista económico nos conduciría a tomar como objeto a las pulsiones -concepto fronterizo y problemático que sería solo localizable entre lo anímico y lo somático (un significante excedente)-, para ver que su lógica traduce un empuje constante cuya única finalidad es, pasando por toda una gama de formaciones de variada índole y sublimaciones, dejar de ser? Freud parece mostrar, en los escritos donde la metapsicología es cuestión, que todo está supeditado a la pulsión, pues si leemos la última frase de Pulsiones y destinos de pulsión: «El destino de pulsión que es la represión será objeto de una indagación posterior [en el artículo que sigue] $\rangle^{41}$, ello parece indicar que el mecanismo que aplica el divorcio entre la representación y el monto de afecto (indistintamente Affektbeträg y Affektwert) a ella adherido, haciendo sí que quede «un símbolo mnémico [Erinnerungssymbol] que habita la conciencia al modo de un parásito $»^{42}$, símbolo que provocará que la insistencia de la que nos habló Lacan, no se deba exclusivamente a un trauma proveniente de lo exterior -esto puede ser contingente-, sino que, en última instancia, dependa de la economía de la pulsión. Es lo que se desprende en De la historia de una neurosis infantil (el «Hombre de los Lobos») ${ }^{43}$,

39 Esta cuestión se retoma también en Tres ensayos de teoría sexual (1905): Freud (1952c), pp. 46-47. Trad. (1978), p. 134.

40 Si bien la cuestión del deseo recorre toda la obra de J. Lacan, en relación con el grafo del deseo reenviamos a los seminarios V y VI: Lacan (1998) y (2013). Véase también el escrito Subversion du sujet et dialectique du désir dans l'inconscient freudien (1960), cf. Lacan (1966), pp. 893-827.

${ }^{41}$ Freud (1952e), p. 232. Trad. (1979c), p. 134.

42 Las neuropsicosis de defensa (1894), cf. Freud (1952a), p. 63. Trad. (1981), p. 51.

43 Texto publicado en 1918, pero ya ultimado en 1914, es la exposición de un caso clínico cuya terapia duró cuatro 
allí donde Freud tuvo que admitir que no importan los recuerdos de cobertura y las posibles transformaciones o creaciones por efecto de retardo en el seno de la Urszene: de lo que se trató siempre fue del olvido de un fantaseo primordial sobre el cual se especula, se sueña, se sublima, se aplican formaciones sustitutivas y reactivas: esto es la economía de la pulsión, la economía de los simulacros.

\section{Otro rodeo por lo (in)hóspito}

Será necesario, antes de volver a la cita de la que partimos de G. Agamben para completarla y comentarla, dar un paso por un momento de la «estética freudiana» que sigue produciendo problemas: el texto Das Unheimliche. Muchas son las páginas dedicadas a este escrito de 1919 y las maneras de abordarlo no son fáciles y pueden incurrir en falsas salidas. Como ya recordamos antes, es Freud el que juega al despiste:

Es muy raro que el psicoanalista se sienta proclive a indagaciones estéticas, por más que a la estética no se la circunscriba a la ciencia de lo bello, sino que se la designe como doctrina de las cualidades de nuestro sentir. El psicoanalista trabaja en otros estratos de la vida anímica y tiene poco que ver con esas mociones de sentimiento amortiguadas, de meta inhibida, tributarias de muchísimas constelaciones concomitantes, que constituyen casi siempre el material de la estética. Sin embargo, aquí y allí sucede que deba interesarse por un ámbito determinado de la estética, pero en tal caso suele tratarse de uno marginal, descuidado por la bibliografía especializada en la materia. Uno de ellos es el de lo «ominoso» [»Unheimliche«]. No hay duda de que pertenece al orden de lo terrorífico, de lo que excita angustia y horror; y es igualmente cierto que esta palabra no siempre se usa en un sentido que se pueda definir de manera tajante. Pero es lícito esperar que una palabra-concepto particular contenga un núcleo que justifique su empleo. Uno querría conocer ese núcleo, que acaso permita diferenciar algo «ominoso» dentro de lo angustioso. ${ }^{44}$

No es importante para los objetivos primeros de este artículo introductorio averiguar las fuentes que Freud consultó, y si en verdad la literatura estética descuidó la cuestión de lo siniestro. Sabemos que Freud propone una barrera lingüística a la entrada de su escrito de 1919, tratando durante numerosas páginas sobre lo problemático de la traducción del término alemán unheimlich. Lo que es importante es la relación con la angustia que Freud establece en las primeras líneas de su texto, a la vez que no puede dejar de considerar que, desde la raíz de Heim -término arcaico para indicar «casa»-, heimlich y unheimlich pueden, si bien son términos opuestos, coincidir $^{45}$. Lo que queda claro en las páginas del escrito freudiano es que lo más inhóspito y siniestro tiene que ver con la muerte y ciertos retornos:

años, de 1910 a 1914. Cf. Freud (1952f), pp. 49-65. Trad. (1979j), pp. 29-46.

44 Lo ominoso (1919), en Freud (1952f), pp. 230-231. Trad. José L. Etcheverry (1979d), p. 219.

45 Ibid., p. 226 de la traducción castellana. Este aspecto fue tratado y subrayado con relación a Heidegger por Ángel Currás Rábade (1977): p. 76. 
A muchos seres humanos les parece ominoso en grado supremo lo que se relaciona de manera íntima con la muerte, con cadáveres y con el retorno de los muertos, con espíritus y aparecidos [mit Geistern und Gespenstern]. En efecto, dijimos que numerosas lenguas modernas no pueden traducir la expresión alemana «una casa unheimlich» como no sea mediante la paráfrasis «una casa poblada de fantasmas». En verdad habríamos debido empezar nuestra indagación por este ejemplo, quizás el más rotundo, de lo ominoso, pero no lo hicimos porque aquí lo ominoso está demasiado contaminado [vermengt] con lo espeluznante y en parte tapado por esto último. ${ }^{46}$

Con esta nota queremos hacer hincapié en un aspecto que se pasa por alto: Freud, en relación con lo Unheimliche quiere llevar a cabo una depuración de esta palabra para que no se la confunda con lo terrorífico y lo espeluznante. Se debería, como recuerda el mismo autor, haber empezado por una casa infestada de fantasmas, lo más aterrador y siniestro, los révenants, aquello que, ni vivo ni muerto, no debería estar allíi ${ }^{47}$. Por límites de tiempo no podremos ahondar sobre la necesidad de seguir releyendo a Freud desde Derrida, pero queremos dejar claro que la idea de preguntarnos por las implicaciones de una «estética freudiana» pasan por la lectura tanto de Lacan como de Derrida y de aquellas cuestiones que los convocaron mutuamente: las freudianas «Erinnerungsspur», "Nachträglichkeit»y «Todestriebe», así como la «huella», la «escritura», el «significante», etc., palabras, todas estas, que deben ser interpretadas cuidadosamente mediante una hermenéutica que aclare las proveniencias y direcciones de cada término en el camino especulativo de los autores. En relación con todo esto, no habrá que olvidar el intento lacaniano de fundamentar un inconsciente como enjambre de (significantes) unos ${ }^{48}$, un inconsciente que resistiría a la interpretación siempre posible de los desplazamientos y condensaciones de los Wahrnehmungszeichen, dejándonos a solas con una superficie surcada de marcas, hendiduras, puntuaciones sin texto ${ }^{49}$ (¿aisthetá?) que siempre excederían hacia un más allá tanto del placer como del saber. Dicha excedencia se encuentra prefigurada en su texto Lituraterre (de 1971, pero publicado en 1973), allí donde solo hay marcas de una huella que es tachadura y surco, hendidura, un retorno a Freud y a sus Bahnungen bajo el signo de la denegación en su confrontación con Derrida ${ }^{50}$.

Volviendo a Lo siniestro, Freud busca algo más que reconducir lo Unheimliche a la aparición de lo inaparente, a aquello que desajusta toda lógica de la presenciaausencia por aparecer allí donde no se lo esperaba y donde no debía estar. De hecho, los ejemplos más depurados de lo siniestro e inhóspito tienen que ver, por una parte, con la Wiederholungszwang:

Sólo de pasada puedo indicar aquí el modo en que lo ominoso del retorno de lo igual puede deducirse de la vida anímica infantil; remito al lector, pues, a una exposición de detalle, ya terminada, que se desarrolla en otro contexto. En lo inconsciente anímico, en efecto, se discierne el imperio de una compulsión de repetición que probablemente

46 Lo ominoso (1919), Freud (1952f), pp. 254-255. Trad. José L. Etcheverry (1979d), p. 241.

47 Ibidem, 241 de la traducción castellana. Sobre estas cuestiones ya se ha escrito un libro que difícilmente podrá ser superado: Spectres de Marx de Derrida.

48 Para ello reenviamos a los seminarios XX y XXIII de Lacan. También en el ya citado texto de J. Rancière (2001) se hace referencia a un inconsciente estético que se acerca a esta concepción lacaniana.

49 La bella expresión la encontramos en Lacan (1966), p. 388.

50 Cf. Lacan (2001), pp. 11-20. 
depende, a su vez, de la naturaleza más íntima de las pulsiones. ${ }^{51}$

Y, por otra parte, con el yo:

Me encontraba solo en mi camarote cuando un sacudón algo más violento del tren hizo que se abriera la puerta de comunicación con el toilette, y apareció ante mí un anciano señor en ropa de cama y que llevaba puesto un gorro de viaje. Supuse que, al salir del baño, situado entre dos camarotes, había equivocado la dirección y por error se había introducido en el mío; me puse de pie para advertírselo, pero me quedé atónito al darme cuenta de que el intruso era mi propia imagen [Eindringling mein eigenes] proyectada en el espejo sobre la puerta de comunicación. Aún recuerdo el profundo disgusto que la aparición me produjo. ${ }^{52}$

Estas dos referencias, aparentemente marginales en el ensayo freudiano, muestran como lo Unheimliche está íntimamente relacionado con el emerger de la pulsión como lo que siempre estuvo allís3. Nada es tan familiar de antiguo y tan extraño a la vez como el propio «yo», ni nada es tan familiarmente inquietante como la compulsión a la repetición, volver una y otra vez a lo mismo hasta que lo mismo aparezca como otro y extraño. Pero esto, una vez más, es el «yo». También Lacan lo supo captar muy bien:

La angustia se produce cuando parece, en el marco, aquello que ya estaba allí, mucho más cerca, en la casa, Heim. Es el huésped, dirán ustedes. En cierto sentido, sí, el huésped desconocido, que se presenta de manera inopinada, tiene que ver con lo que se encuentra en lo unheimlich [...] Este huésped es ya lo que había virado hacia lo hostil [...] Este huésped, en el sentido corriente del término, no es lo heimlich, no es el habitante de la casa, es lo hostil domesticado, apaciguado, admitido. Lo que es Heim, lo que forma parte del Geheimnis [secreto, clandestino], nunca pasa por los rodeos, las redes y los tamices del reconocimiento. ${ }^{54}$

Esto es bastante revelador incluso pensado en la lógica del révenant: el reaparecido no es inquietante por lo que tiene de extraño y extranjero, por el hecho de que eso no debería estar allí, sino por lo que tiene de familiar, por el mensaje unheimlich que porta consigo: siempre estuvimos aquí, en la casa, en lo familiar, en lo (in)hóspito. O lo que es lo mismo: desde la perspectiva de la Trieblehre, en lo esencial de un ser hablante hay desarrollos, pero no progreso. Por ello podrá escribir Freud que «el

51 Cf. Freud (1952f), p. 251. Trad. (1979d), p. 238. El «otro contexto» en la cita se refiere al texto Más allá del principio de placer, escrito en la misma época.

52 Ibid., pp. 262-263, n. 1 y p. 247, n. 30 de la traducción castellana.

53 Esto parece decir, en última instancia, la pulsión: siempre estuvimos aquí, en la casa. El mejor ejemplo que reúne los dos aspectos de lo unheimlich -el «eso no debería estar allí» y el «siempre estuvimos aquí»- lo encontramos magníficamente expuesto al final del filme The Shining (1980) de S. Kubrick. Sin entrar en las divergencias con la novela de S. King, hacia el final del filme vemos, por un lado, lo unheimlich como manifestación de los espectros en el Overlook Hotel (que responde al «eso no debería estar allí»), y, ya en las últimas secuencias del film, lo unheimlich como lo antiguamente familiar que se desvela allí cuándo se nos muestra una foto de Jack Torrance (el personaje interpretado por J. Nicholson) fechada 4 de julio de 1921, es decir, «siempre estuvimos aquí». En el «orden» pulsional hay desarrollo, pero no progreso. Más adelante trataremos de explicar a lo que nos referimos.

$54 \quad$ Lacan (2004), p. 91. 
prefijo "un" de la palabra unheimlich es la marca de la represión.» ${ }^{55}$, precisamente porque obedece al destino de pulsión que es la Verdrängung como supresión y como desplazamiento: lo inhóspito inquietante es (está desplazado a lo largo de) la Heim.

\title{
4. Implicaciones de una «estética freudiana»
}

Ahora que la ley económica de la pulsión parece haber indicado que siempre estamos trabajando con simulacros - el objeto no coincide con la meta ni con el fin-, que siempre estuvieron allí, en el Heim, podemos ofrecer la cita completa de la que partimos:

\begin{abstract}
Así nos convencemos de que aún bajo el imperio del principio de placer existen suficientes medios y vías para convertir en objeto de recuerdo y elaboración anímica lo que en sí mismo es displacentero. Una estética de inspiración económica debería ocuparse de estos casos y situaciones que desembocan en una ganancia final de placer; pero no nos sirven de nada para nuestro propósito, pues presuponen la existencia y el imperio del principio de placer y no atestiguan la acción de tendencias situadas más allá de este, vale decir, tendencias que serían más originarias que el principio de placer e independientes de él. ${ }^{56}$
\end{abstract}

Lo que leemos contradice en parte lo publicado por Agamben al invalidar cualquier proyecto de una estética de inspiración económica. En verdad, la economía de la que trata Freud en nada tiene que ver con lo que comúnmente se entiende bajo este término, sino con una ley en y por la cual es difícil comprender dónde está el beneficio. Por lo que se pude discernir de la cita, la economía del principio de placer permitiría siempre un funcionamiento: el tren, para utilizar un símil muy conocido, marcharía sin problemas, pues hay suficientes medios para la conversión de cualquier objeto según fines y metas. O inversamente, para la meta, un objeto dado siempre puede ser convertido en equivalente de otro. Pero Freud atisba algo más -entonces quizá sí se trate de una aísthēsis- por lo que puede afirmar que la economía del principio de placer (la conversión de cualquier objeto según fines relacionados con el placer y el dolor, y, también, metas para las cuales las permutaciones de objeto serán, en principio, ilimitadas en la relación con el placer y el dolor), es desbaratada por otra economía que hace inútil las formaciones reactivas, sustitutivas y las sublimaciones. La pulsión, si queremos, es esta diferencia, la economía del simulacro que invalida cualquier conversión ${ }^{57}$ de algo (o de nada) según fines, pues en el origen no hubo más que simulacros, huellas propiciadoras de un fantaseo primordial siempre perseguido y que, de continuo, se olvida. Estas «huellas» que apuntan a un más allá del principio de placer invalidan, tal y como la teoría requiere, cualquier tipo de trabajo o de formación sustitutiva, y es Freud quién lo recuerda: ningún fetiche o formación sustitutiva, ninguna mascarada neurótica o formación reactiva y ninguna sublimación (¿incluso artística?) podrán domeñar la Wiederholungszwang. Es por ello por lo que, si hubiera una «estética freudiana», no habría que buscarla en un «psicoanálisis del arte o del artista», o en una comparación-explicación de obras artísticas y teorías

\footnotetext{
Freud (1952f), p. 254. Trad. José L. Etcheverry (1979d), p. 241.

Freud (1952g), p. 14. Trad. José L. Etcheverry (1979e), p. 17.

$\mathrm{O}$ «perversión»: para el caso es lo mismo.
} 
psicoanalíticas, sino, y es nuestra apuesta, en la parte explícitamente estética que podemos encontrar en Freud bajo recursos descriptivos como: la Erinnerungsspur, la Umschrift, los Wahrnehmungszeichen y la Todestriebe. Estos términos, y en particular los tres primeros, reclaman una mayor cercanía con el proyecto estético de Baumgarten del analogon rationis, pues son los recursos para que algo como el «inconsciente» sea susceptible de «comparecer». Con esto no estamos afirmando que lo relativo a las relaciones psicoanálisis-arte no deba ser interrogado. Simplemente nuestra propuesta va por otro lado.

La «estética freudiana» que proponemos sería algo que estaría comprendido -junto a lo que conocemos como Psychoanalyse, metapsychologische Darstellung y Trieblehre-dentro de la nihilidad entendida como el progresivo allanamiento de todo recurso simbólico, y, por ello mismo, dentro de la historia de la filosofía. Dicho esto, tendremos una serie de apariencias (las mencionadas conversiones de cualesquiera objetos según fines, etc.) de la esencia (lo trascendental: la pulsión). Las primeras, lo fenoménico de la pulsión, serían el campo dónde la «estética freudiana» llevaría a cabo el trabajo preparatorio como parte de la Trieblehre, aspecto siempre perseguido por Freud y nunca fundamentado del todo.

El primer paso, entonces, no podría más que ser el de una estética de la Todestriebe que nos conduciría a encararla por «cómo se presenta»: una extraña economía de la animación de lo inerte ${ }^{58}$ tal y como se lee en un pasaje ya citado de Más allá del principio del placer: «En algún momento, por una intervención de fuerzas que todavía nos resulta enteramente inimaginable, se suscitaron en la materia inanimada (unbelebter Materie) las propiedades de la vida». Así nace la primera pulsión: como un Leblosen zurückzukehren, un regreso hacia lo anterior no animado, pulsión que, entonces, estaría siempre entre lo que llamamos «muerte» y lo que llamamos «vida», pero que habitaría un cierto estrato (Schicht) donde se gestarían las transcripciones de las huellas y sus transposiciones, elementos que, a nuestro juicio, nos devuelven a una problemática «estética». Se podría puntualizar que no es propiamente una estética si también hablamos en términos económicos (conversiones, sustituciones, equivalencias), pero el hecho de partir de las especulaciones freudianas -incluso en contra de ellas- parecen corroborar algunas conclusiones que determinados autores han suscrito con fuerza: no parece haber una estética que no comporte una economía ${ }^{59}$. Este texto pretende abrir el paso a una «estética freudiana» como momento preparatorio hacia el discernimiento de lo que Freud atisba como «animación de lo inerte»: el desajuste siempre repetido y pujante de las conversiones de cualquier objeto (simulacro) según fines y metas (más allá del principio de placer), o, lo que es equivalente, el alcance siempre retardado de metas a través de objetos dados que son convertidos en equivalentes de otros. Proponemos esto porque creemos que lo que se está apuntando en estas líneas es una marca de la tardomodernidad, y la crítica de esta es tarea filosófica en su sentido más propio.

58 Con la «animación de lo inerte» hemos, de manera voluntaria, conjurado otro espectro, el de Marx. La relación entre el discernimiento de la economía política y la doctrina de las pulsiones es una tarea urgente y todavía pendiente.

59 Nos referimos a las conclusiones de Calasso en Déesses entretenues (1975), cf., Calasso R. (1991), p. 250 y sigs., y a las de Cacciari (1997), p. 121. Dichas conclusiones se apoyan a su vez en otros autores como Marx, Baudelaire, Benjamin y Klossowski. 


\section{Post-scriptum}

Con relación al final de nuestro escrito queremos hacer unas puntualizaciones sobre una cuestión alrededor de la cual se siguen produciendo discusiones: los fines de Freud y su lugar dentro de la historia del pensamiento. Desde su obra Lo inconsciente, parece obvio que «inconsciente» no fue más que una palabra para dar una descripción de eso para lo cual Freud quiso, a partir de un determinado momento, otorgar otro tipo de análisis: una exposición metapsicológica. Es decir, añadir a los mencionados caracteres tópicos y dinámicos otro matiz, el económico (algo que, de por sí solo, no concluye la Trieblehre, sino que la amplía). Solo esto otorga a una exposición la posibilidad de ser llamada «metapsicológica». ¿Exposición de qué? De la psique, lo que constituye para Freud cuestión. Fijémonos en uno de los textos teóricos más complejos de Freud, Inhibición, sintoma y angustia, en cuya cita se aprecia claramente la diferencia entre una descripción y una exposición:

A raíz de un peligro externo, el ser orgánico inicia un intento de huida: primero quita la investidura a la percepción de lo peligroso; luego discierne que el medio más eficaz es realizar acciones musculares tales que vuelvan imposible la percepción del peligro, aun no rehusándose a ella, vale decir: sustraerse del campo de acción del peligro. Pues bien; la represión equivale a un tal intento de huida. El yo quita la investidura (preconsciente) de la agencia representante de pulsión que es preciso reprimir \{desalojar\}, y la emplea para el desprendimiento de displacer (de angustia). Puede que no sea nada simple el problema del modo en que se engendra la angustia a raíz de la represión; empero, se tiene el derecho a retener la idea de que el yo es el genuino almacigo de la angustia, y a rechazar la concepción anterior, según la cual la energía de investidura de la moción reprimida se mudaba automáticamente en angustia. Al expresarme así anteriormente, proporcioné una descripción fenomenológica [phänomenologische Beschreibung], no una exposición metapsicológica [metapsychologische Darstellung]. ${ }^{60}$

La «metapsicología», que tantos quebraderos de cabeza sigue provocando, es una parte teórica dentro de la más general Trieblehre. Que Freud, en nombre del pasado y de una terapia al resguardo de la IPA fundada pocos años antes (Nuremberg, 1910), siguiera llamándola «psicoanálisis», no debe distraernos de lo que Freud nos legó: la Wiederholungszwang, la nominación mejor lograda para describir el funcionamiento de la pulsión, algo que hace ya imposible cualquier sanación por medio de la terapia. No se trata ya de levantar síntomas o de disolverlos, pues la compulsión de repetición es estructura, y no formación de compromiso como los demás síntomas.

Un indicio más, muy significativo, es el que extraemos de lo que se considera el testamento freudiano, Análisis terminable e interminable (1937):

Acaso no sea ocioso, para evitar malentendidos, puntualizar con más precisión lo que ha de entenderse por la frase «tramitación duradera de una exigencia pulsional». No es, por cierto, que se la haga desaparecer de suerte que nunca más dé noticias de ella. Esto es en general imposible, y tampoco sería deseable. No, queremos significar otra cosa, que en términos aproximados se puede designar como el «domeñamiento» [Bändigung] de la pulsión: esto quiere decir que la pulsión es admitida en su totalidad dentro de la armonía

60 Freud (1952h), pp. 119-120. Trad. (1979g), pp. 88-89. 
del yo, es asequible a toda clase de influjos por las otras aspiraciones que hay en el interior del yo, y ya no sigue más su camino propio hacia la satisfacción. Si se pregunta por qué derroteros y con qué medios acontece ello, no es fácil responder. Uno no puede menos que decirse: «Entonces es preciso que intervenga la bruja». La bruja metapsicología, quiere decir. Sin un especular y un teorizar metapsicológicos -a punto estuve de decir: fantasear- no se da aquí un solo paso adelante. ${ }^{61}$

Con este «Phantasieren» que se arriesga a confundirse con una «metapsychologisches Spekulieren und Theoretisieren», paso sin el cual es imposible avanzar, damos por concluido este escrito sobre las implicaciones de una fantaseada «estética freudiana», sin la cual, precisamente por lo que implica, sería improbable dar pasos en relación con el esclarecimiento de determinadas cuestiones fundamentales que pertenecen a la filosofía en su sentido más fuerte.

\section{Referencias bibliográficas}

Agamben, G. (2017): Gusto, Adriana Hidalgo editora, Buenos Aires.

Baumgarten, A. G. (1963): Metaphysica, Georg Holms Hildesheim, Darmstadt.

Baumgarten, A. G. (2007): Ästhetik, Felix Meiner Verlag GmbH, Hamburg.

Cacciari, M. (1997): L'arcipelago, Adelphi, Milano.

Calasso, R. (1991): I quarantanove gradini, Adelphi, Milano.

Craveri, B. (2001): La civiltà della conversazione, Adelphi, Milano.

Currás Rábade, Á. (1977): "Heidegger: el arduo sosiego del exilio", Logos. Anales del seminario de Metafísica, Vol. 12, n. 12, pp. 59-94.

Derrida, J. (1980): La carte postale. De Socrate à Freud et au-delà, Flammarion, Paris.

Derrida, J. (1993) : Spectres de Marx, Éditions Galilée, Paris.

Derrida, J. (1995) : Mal d'archive, Éditions Galilée, Paris.

Ferraris, M.; Kobau, P. (2001): L'altra estetica, Einaudi, Torino.

Ferraris, M. (1997, 2011²): Estetica razionale, Raffaello Cortina Editore, Milano.

Franzini, E.; Mazzocut-Mis, M. (1996): Estetica. I nomi, i concetti, le correnti, Mondadori, Milano.

Freud, S. (1952a): Gesammelte Werke, Band I 1892-1899, London, Imago Publishing Co.

Freud, S. (1952b): Gesammelte Werke, Band II/III 1900-1901. London: Imago Publishing Co.

Freud, S. (1952c): Gesammelte Werke, Band V 1900-1901. London: Imago Publisching Co.

Freud, S. (1952d): Gesammelte Werke, Band VII 1913-1917. London: Imago Publishing Co.

Freud, S. (1952e): Gesammelte Werke, Band X 1913-1917. London: Imago Publisching Co.

Freud, S. (1952f): Gesammelte Werke, Band XII 1917-1920. London: Imago Publisching Co.

Freud, S. (1952g): Gesammelte Werke, Band XIII 1920-1924.

Freud, S. (1952h): Gesammelte Werke, Band XIV 1925-1931. London: Imago Publishing Co. Freud, S. (1952i): Gesammelte Werke, Band XVI 1932-1939. London: Imago Publishing Co. Freud, S. (1952j): Gesammelte Werke, Band XVII 1892-1939. London: Imago Publishing Co. Freud, S. (1986): Briefe an Wilhelm Fliess 1887-1904, Ungekürtze Ausgabe, Frankfurt A/M: Fisher. 
Freud, S. (1981): Las neuropsicosis de defensa (1894). Obras completas vol. III. Trad. José L. Etcheverry, Buenos Aires: Amorrortu editores.

Freud, S. (1979a): La interpretación de los sueños (1900-01). Obras completas vol. IV y V, Buenos Aires: Amorrortu editores.

Freud, S. (1978): Tres ensayos de teoría sexual (1905). Obras completas vol. IX, Buenos Aires: Amorrortu editores.

Freud, S. (1979b): El delirio y los sueños en la «Gradiva» de W. Jensen (1907[1906]). Obras completas vol. IX, Buenos Aires: Amorrortu editores.

Freud, S. (1979b): El creador literario y el fantaseo (1908[1907]). Obras completas vol. IX, Buenos Aires: Amorrortu editores.

Freud, S. (1980a): El Moisés de Miguel Ángel (1913). Obras completas vol. XIII. Trad. José L. Etcheverry, Buenos Aires: Amorrortu editores.

Freud, S. (1979c): Pulsiones y destinos de pulsión (1915). Obras completas vol. XIV, Buenos Aires: Amorrortu editores.

Freud, S. (1979c): El inconsciente (1915). Obras completas vol. XIV, Buenos Aires: Amorrortu editores.

Freud, S. (1979d): De la historia de una neurosis infantil (el «Hombre de los Lobos») (1918 [1914]). Obras completas vol. XVII. Buenos Aires: Amorrortu editores.

Freud, S. (1979d): Lo ominoso (1919). Obras completas vol. XVII, Buenos Aires: Amorrortu editores.

Freud, S. (1979e): Más allá del principio de placer (1920 [1919]). Obras completas vol. XVIII, Buenos Aires: Amorrortu editores.

Freud, S. (1979f): Presentación autobiográfica (1925 [1924]). Obras completas vol. XX, Buenos Aires: Amorrortu editores.

Freud, S. (1979g): Inhibición, síntoma y angustia (1926 [1925]). Obras completas vol. XXI, Buenos Aires: Amorrortu editores.

Freud, S. (1980b): Análisis terminable e interminable (1937). Obras completas vol. XXIII, Buenos Aires, Amorrortu editores.

Gombrich, E. H. (1966): «Freud's Aesthetics», Encounter, vol. XXVI, n. 1.

Heidegger, M. (1975): Nietzsche (GA, 6,1; 6,2), Francfort, Klostermann.

Lacan, J. (1966): Écrits. Paris: Éditions du Seuil.

Lacan, J. (1998) Le Séminaire de Jacques Lacan, Livre V. Les formations de l'inconscient, 1957-1958. Paris : Éditions du Seuil.

Lacan, J. (2013) Le Séminaire de Jacques Lacan, Livre VI. Le désir et son interprétation, 1958-1959. Paris: Éditions de La Martinière.

Lacan, J. (2004) Le Séminaire de Jacques Lacan, Livre X. L'angoisse, 1962-1963. Paris : Édition du Seuil.

Lacan, J. (2001) Autre écrits. Paris: Édition du Seuil.

Laplanche, J.; Pontalis, J.-B. (2004): Diccionario de psicoanálisis, Buenos Aires: Paidós.

Martínez Marzoa, F. (1994, 2010): Historia de la Filosofía I, Madrid: Istmo.

Martínez Marzoa, F. (1995): Historia de la Filosofía Antigua. Madrid: Akal.

Martínez Marzoa, F. (1996): Ser y diálogo, Madrid: Istmo.

Martínez Marzoa, F. (2007): Muestras de Platón, Madrid: Abada.

Moreno Tirado, G. (2016): «Decaimiento o enfermedad del lenguaje. Un diálogo entre Heidegger y el psicoanálisis», Differenz, Revista internacional de estudios heideggerianos y sus derivas contemporáneas, ISSN: 2386-4877, n. ${ }^{\circ}$ 2, pp. 67-84: http://institucional. us.es/differenz/index.php?page $=$ numero-2-julio-de-2016. 
Moreno Tirado, G. (2020): «El “concepto hermenéutico". Una interpretación del juicio estético puro kantiano desde Heidegger», Con-Textos Kantianos, ISSN: 2386-7655, n. ${ }^{\circ}$ 12, pp. 454-477.

Pizzo Russo, L. (2015): Psicologia delle arti. Palermo: Centro Internazionale Studi di Estetica, Aesthetica Preprint.

Praz, M. (2002): Bellezza e bizzarria. Saggi scelti. Milano, Mondadori.

Rancière, J. (2001): L'inconscient esthétique. Paris: Éditions Galilée.

Ricoeur, P. (2008): Écrits et conférences 1. Autour de la psychanalyse. Paris, Éditions du Seuil.

Russo, L. (1983): La nascita dell'estetica di Freud. Bologna: Il Mulino. 